Article

\title{
Brute Force Composition Scanning with a CALPHAD Database to Find Low Temperature Body Centered Cubic High Entropy Alloys
}

\author{
T. P. C. Klaver *, D. Simonovic and M. H. F. Sluiter ${ }^{\mathbb{D}}$
}

Department of Materials Science and Engineering, Delft University of Technology, 2628 CD Delft, The Netherlands; darko.simonovic@gmail.com (D.S.); M.H.F.Sluiter@tudelft.nl (M.H.F.S.)

* Correspondence: klaver2@gmail.com; Tel.: +31-15-2784-345

Received: 11 October 2018; Accepted: 26 November 2018; Published: 29 November 2018

\begin{abstract}
We used the Thermo-Calc High Entropy Alloy CALPHAD database to determine the stable phases of $\mathrm{AlCrMnNbTiV}, \mathrm{AlCrMoNbTiV}, \mathrm{AlCrFeTiV}$ and $\mathrm{AlCrMnMoTi}$ alloys from 800 to $2800 \mathrm{~K}$. The concentrations of elements were varied from 1-49 atom $\%$. A five- or six-dimensional grid is constructed, with stable phases calculated at each grid point. Thermo-Calc was used as a massive parallel tool and three million compositions were calculated, resulting in tens of thousands of compositions for which the alloys formed a single disordered body centered cubic (bcc) phase at $800 \mathrm{~K}$. By filtering out alloy compositions for which a disordered single phase persists down to $800 \mathrm{~K}$, composition 'islands' of high entropy alloys are determined in composition space. The sizes and shapes of such islands provide information about which element combinations have good high entropy alloy forming qualities as well as about the role of individual elements within an alloy. In most cases disordered single phases are formed most readily at low temperature when several elements are almost entirely excluded, resulting in essentially ternary alloys. We determined which compositions lie near the centers of the high entropy alloy islands and therefore remain high entropy islands under small composition changes. These island center compositions are predicted to be high entropy alloys with the greatest certainty and make good candidates for experimental verification. The search for high entropy islands can be conducted subject to constraints, e.g., requiring a minimum amount of $\mathrm{Al}$ and/or $\mathrm{Cr}$ to promote oxidation resistance. Imposing such constraints rapidly diminishes the number of high entropy alloy compositions, in some cases to zero. We find that $\mathrm{AlCrMnNbTiV}$ and $\mathrm{AlCrMoNbTiV}$ are relatively good high entropy alloy formers, $\mathrm{AlCrFeTiV}$ is a poor high entropy alloy former, while AlCrMnMoTi is a poor high entropy alloy former at $800 \mathrm{~K}$ but quickly becomes a better high entropy alloy former with increasing temperature.
\end{abstract}

Keywords: high entropy alloy; bcc; phase stability; CALPHAD; composition scanning

\section{Introduction}

High entropy alloys (HEAs) are at present a very active field of research within metallurgy. The vast number of possible compositions promises a very broad range of properties. While the vast majority of (near) equi-atomic combinations of alloying elements lead to alloys with poor properties, the small fraction of combinations with good properties still provides very promising prospects, spurring very active research in this area.

Originally, HEAs were defined as alloys with five or more principal elements in (near) equi-atomic amounts, which form a single disordered phase on a simple crystal lattice. Configurational entropy was thought to be the main stabilizing factor, though it was soon shown that other factors can be more important, see e.g., [1]. More recently, the focus of attention has widened. More alloys 
that are not (near) equi-atomic have been investigated [2]. Carbon and/or nitrogen have been deliberately introduced to steer ferritic/austenic stability and to form finely dispersed carbides and/or nitrides to improve mechanical properties, see e.g., [3]. Compositions are chosen to deliberately create multi-phase materials that have better mechanical properties [4,5]. Stacking fault energies and relative phase stabilities in multi-phase materials are engineered to induce TRIP and/or TWIP deformation mechanisms [6-12]. Despite the extensive research effort on HEAs, the number of true HEAs found is still rather limited [13]. The vast majority of compositions lead to the formation of alloys with very brittle phases, like Laves and sigma phases [14]. Even many of the compositions that lead to alloys with good properties for applications are not truly HEAs at lower temperature. These alloys (sometimes referred to as compositionally complex alloys) may be HEAs just below the solidification temperature, but at lower temperature their equilibrium state includes additional phases $[15,16]$. They often have good low temperature properties thanks to the sluggish formation of additional phases, which allows the disordered single phase to persist as a meta-stable state at lower temperature.

In this work we focus on finding HEAs that retain their single disordered phase down to relatively low temperature, consisting in part of elements that promote oxidation resistance ( $\mathrm{Al}$ up to high temperature, $\mathrm{Cr}$ up to intermediate temperature in environments free of water vapour). The number of non-equi-atomic composition variations with five or more elements is so large that experimental testing, even with modern high-throughput screening using samples with composition gradients, is no longer feasible. Computationally however, using CALPHAD databases to determine the stable phases as a function of temperature on a fine grid in the composition space is possible. For the six element alloys $\mathrm{AlCrMnNbTiV}$ and $\mathrm{AlCrMoNbTiV}$, and five element alloys AlCrFeTiV and AlCrMnMoTi, and their constituent alloys, we determined in a five (four) dimensional composition space where the 'islands' of low temperature HEA stability are located, i.e., for which compositions a single disordered phase remains stable down to low temperature. Apart from determining islands of low temperature HEA stability we also determine where the 'centers' of the islands are, i.e., which compositions remain HEAs under small compositional changes. These compositions are also likely to have some margin against the inevitable error inherent in the CALPHAD method, see e.g., the mismatches in the comparison between CALPHAD predicitons and experimental results drawn up by Saal et al. [15]. The island centre compositions are predicted to be low temperature HEAs with the greatest certainty and are good candidates for experimental verification. Apart from selecting compositions corresponding to the centers of islands of HEA stability, constraints can be imposed. For example, minimum amounts of $\mathrm{Al}$ and/or $\mathrm{Cr}$ can be required to promote oxidation resistance. Also, alloys can be selected for a narrow solidification temperature range to limit segregation during solidification.

The outline of this paper is as follows: in Section 2 we provide details on our computational approach. In Section 3 we first explain our choice of the five and six element alloys we investigated and present results of a simple composition optimization for these alloys. We then present results of convergence testing of the concentration step size used in brute force scanning of the composition space for these alloys. After that, we look at the overall HEA forming qualities of the alloys and the roles that individual elements play in them through binary element projections. Finally, we present results about the islands of HEA stability for our alloys, without and with constraints for minimum concentrations of certain elements. Conclusions are reported in Section 4.

\section{Computational Details}

The Thermo-Calc (TC) implementation of the CALPHAD method was used to calculate stable phases. The TC high entropy alloy v2.1 database (TCHEA2.1 $[17,18]$ ) was used within TC v2017b or 2018a, run under linux. The TCHEA2.1 database contains data for the elements $\mathrm{Al}, \mathrm{C}, \mathrm{Co}, \mathrm{Cr}, \mathrm{Cu}$, $\mathrm{Fe}, \mathrm{Hf}, \mathrm{Mn}, \mathrm{Mo}, \mathrm{N}, \mathrm{Nb}, \mathrm{Ni}, \mathrm{Re}, \mathrm{Ru}, \mathrm{Si}, \mathrm{Ta}, \mathrm{Ti}, \mathrm{V}, \mathrm{W}$ and $\mathrm{Zr}$. For these elements, full information on all binary systems and 135 ternary systems is included, as well as partial information from another 308 ternary systems. Equilibrium data for some of the elements (including Fe) is available only for $\sim 500^{\circ} \mathrm{C}$ and above. To avoid the hazards of extrapolation, our calculations apply to the temperature 
range $800-2800 \mathrm{~K}$. Below $800 \mathrm{~K}$ diffusion is exceedingly sluggish in transition metal HEAs, so that equilibrium calculations are in any case more applicable to the higher temperature ranges. We found that calculations over a continuous temperature range with TCHEA2.1 enter into infinite loops every few dozen compositions, making automated high-throughput calculations ineffective. Also, results are at times calculated over incomplete temperature ranges. Calculations did not go into infinite loops when calculated with a different TC database (SSOL) or when data was calculated at discrete temperatures rather than continuously over a temperature range. Hence, we calculated data with TCHEA2.1 every $50 \mathrm{~K}$ in the 800-2800 K range (41 temperatures).

We employed a high throughput approach that is in some ways similar to the high-throughput method used by Senkov et al. $[19,20]$. In their extensive study, the Pandat implementation of the CALPHAD method was used to calculate the equilibrium phases for over 100,000 equi-atomic alloys. Here we determine equilibrium phases for a large number of non-equi-atomic compositions for four alloys. We used the Console.sh command line interface within TC to run typically 100 calculations in parallel on single cpu cores of a computing cluster. The calculation of the stable phases and their fractions at 41 temperatures takes less than a minute on one cpu core, allowing throughput of a few thousand compositions per core per day. For this work we calculated 3 million compositions in total. While e.g., using a genetic algorithm to find HEA compositions [21], possibly in combination with a constraint satisfaction algorithm [22] or performing a targeted search that optimizes an objective function (e.g., narrow solidification temperature range or single disordered phase stability down to low temperature) under constraints [23] are approaches that are all far less computationally demanding, using TC as a high throughput tool is not much limited by the required cpu time or the disk space required to store input and output files. Analysis can be time consuming if it is done post hoc in serial over hundreds of thousands of output files. Analysis should ideally be included right after each TC calculation so that it is carried out in parallel, either using external tools or the TC_Python module.

\section{Results and Discussion}

\subsection{Selection of Alloys, Extending the HEA Temperature Range}

HEAs containing $\mathrm{Al}, \mathrm{Cr}$ and $\mathrm{Ti}$ are rather likely to have a bcc crystal structure. Pure $\mathrm{Cr}$ has a bcc crystal structure and while Ti has an hcp structure at room temperature, it assumes a bcc structure above $1155 \mathrm{~K}$. While pure $\mathrm{Al}$ has an fcc crystal lattice, it is known to promote the bcc structure in transition metal based HEAs [24]. The work by Senkov et al. [19,20] reported both five element and six element bcc HEAs (Tables 14 and 15 in [19]). TCHEA2.1 did not confirm all bcc HEAs predicted in [22], but several six element HEAs containing $\mathrm{Al}$ and $\mathrm{Cr}$, including $\mathrm{AlCrMnNbTiV}$ and $\mathrm{AlCrMoNbTiV}$, were confirmed to be HEAs. AlCrMnNbTiV is predicted to be a single disordered bcc phase from 1550-1750 K, AlCrMoNbTiV from 1200-2100 K. According to TCHEA2.1 the five element HEA $\mathrm{AlCrTaTiV}$ starts to form a sigma phase just before solidification is complete. AlCrFeTiV is predicted to be a disordered single bcc phase from 1050-1800 K, AlCrMnMoTi from 1150-1800 K. We focused our work on AlCrMnNbTiV, AlCrMoNbTiV, AlCrFeTiV and AlCrMnMoTi.

For practical applications of these four series of alloys, it is preferable that the temperature at which other (brittle) phases appear is decreased and the amount of other phases formed is reduced. A simple way to achieve this is to determine what the composition of the disordered bcc phase and alternate phases is at a lower temperature, where multiple phases have formed. If the alternate phases were removed, the remaining bcc phase then forms a HEA at the lower temperature. This was tried for multiple iterations for $\mathrm{AlCrMnNbTiV}$, see Figure 1.

Obviously, altering the concentrations of the individual elements within a HEA can be very effective in maintaining the HEA to a lower temperature and reducing the amount of alternate phases once they start to form. However, this way of strengthening the HEA character of an alloy produces a HEA that at low temperature is on the boundary of the HEA single phase region and the two or more phase region containing undesirable secondary phases. 

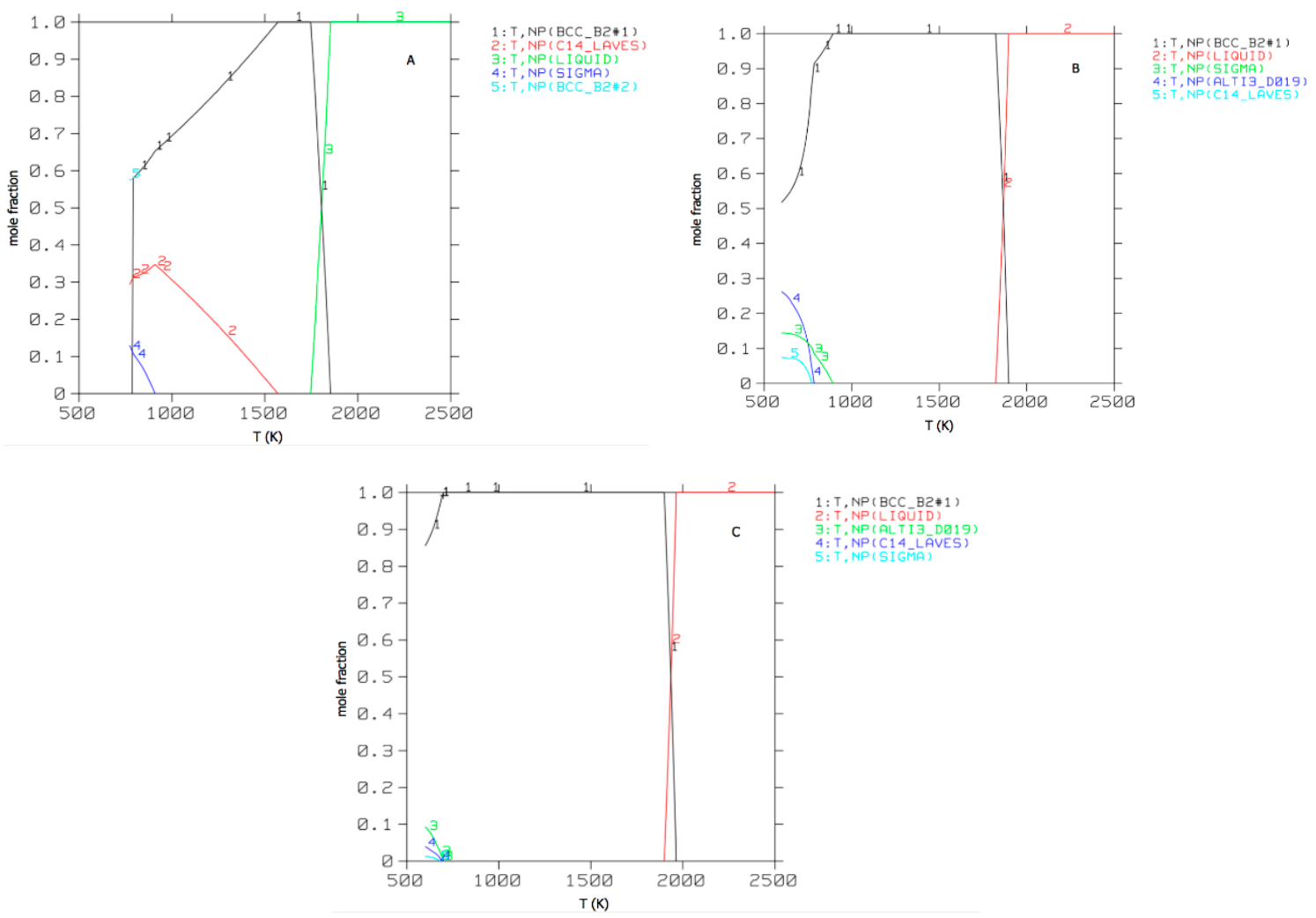

Figure 1. Phase fractions as a function of temperature for (A) equi-atomic $\mathrm{AlCrMnNbTiV}$ (B) $\mathrm{Al}_{18} \mathrm{Cr}_{10} \mathrm{Mn}_{13} \mathrm{Nb}_{12} \mathrm{Ti}_{21} \mathrm{~V}_{26}$ (C) $\mathrm{Al}_{15} \mathrm{Cr}_{12} \mathrm{Mn}_{17} \mathrm{Nb}_{3} \mathrm{Ti}_{10} \mathrm{~V}_{43}$.

The smallest change in composition in some directions already leads to the formation of secondary phases. In order to find an alloy that is a HEA 'with margin to spare', we want to find the compositions that remain HEAs under all small composition changes.

\subsection{Convergence Testing for Scanning Part of the Composition Space}

Scanning all possible five and six element alloy compositions at fine $1 \%$ increments requires going through more compositions than is feasible. In order to limit the number of compositions required, we limit the portion of the composition space that we cover and for that limited part of the composition space, we conduct convergence tests of the concentration increment, to see how fine a mesh is required. We limit the part of the composition space by requiring that no element in a HEA should be a majority constituent, i.e., the concentration of any element should be $<50$ atom $\%$. Within the selected part of the composition space, atom percentages are varied from 1 to $49 \%$ for all but one element and the concentration of the last element is set to reach $100 \%$ in total. If the concentration of the last element has to be negative or larger than $50 \%$, the composition is rejected. For five/six element alloys, each element has the role of 'filler-up' once and that of 'independent variable' four/five times. It should be noted that while the independent and filler-up elements have the same concentration increment, the possible concentrations of the filler-up element are shifted compared to those of the other elements. For example, the composition closest to a binary alloy has $49 \%$ of one element, $1 \%$ for four elements, leaving $47 \%$ for the filler-up element. Thus with a $4 \%$ concentration increment, the independently varied elements have concentrations of $49,45, \ldots 5,1 \%$ while the filler-up element has concentrations of $47,43, \ldots, 7,3 \%$. Thus the possible element concentrations of the independently varied and filler-up elements are on sub-grids that have the same spacing but are shifted from each other. Hence a $4 \%$ concentration increment will result in some element concentrations being only $2 \%$ apart. Following the scheme outlined above, the numbers of compositions for five and six element alloys are as shown in Table 1. 
Table 1. Numbers of compositions for five and six element alloys for different concentration spacings.

\begin{tabular}{ccc}
\hline \multirow{2}{*}{ Concentration Spacing (\%) } & \multicolumn{2}{c}{ Compositions } \\
\cline { 2 - 3 } & Five elements & Six elements \\
\hline 6 & 13,530 & 74,412 \\
4 & 60,905 & 473,382 \\
2 & 862,750 & $2,114,580 *$ \\
\hline
\end{tabular}

${ }^{*}$ not calculated with TC in our study.

The results we are most interested in are the shapes of low temperature islands of HEA stability. The convergence tests should therefore determine how much these vary with the concentration spacing. We show a number of two-dimensional projections for $\mathrm{Al}_{\mathrm{a}} \mathrm{Cr}_{\mathrm{b}} \mathrm{Fe}_{\mathrm{c}} \mathrm{Ti}_{\mathrm{d}} \mathrm{V}_{1-\mathrm{a}-\mathrm{b}-\mathrm{c}-\mathrm{d}}$ in Figure 2 and for $\mathrm{Al}_{\mathrm{a}} \mathrm{Cr}_{\mathrm{b}} \mathrm{Mn}_{\mathrm{c}} \mathrm{Nb}_{\mathrm{d}} \mathrm{Ti}_{\mathrm{e}} \mathrm{V}_{1-\mathrm{a}-\mathrm{b}-\mathrm{c}-\mathrm{d}-\mathrm{e}}$ in Figure 3.
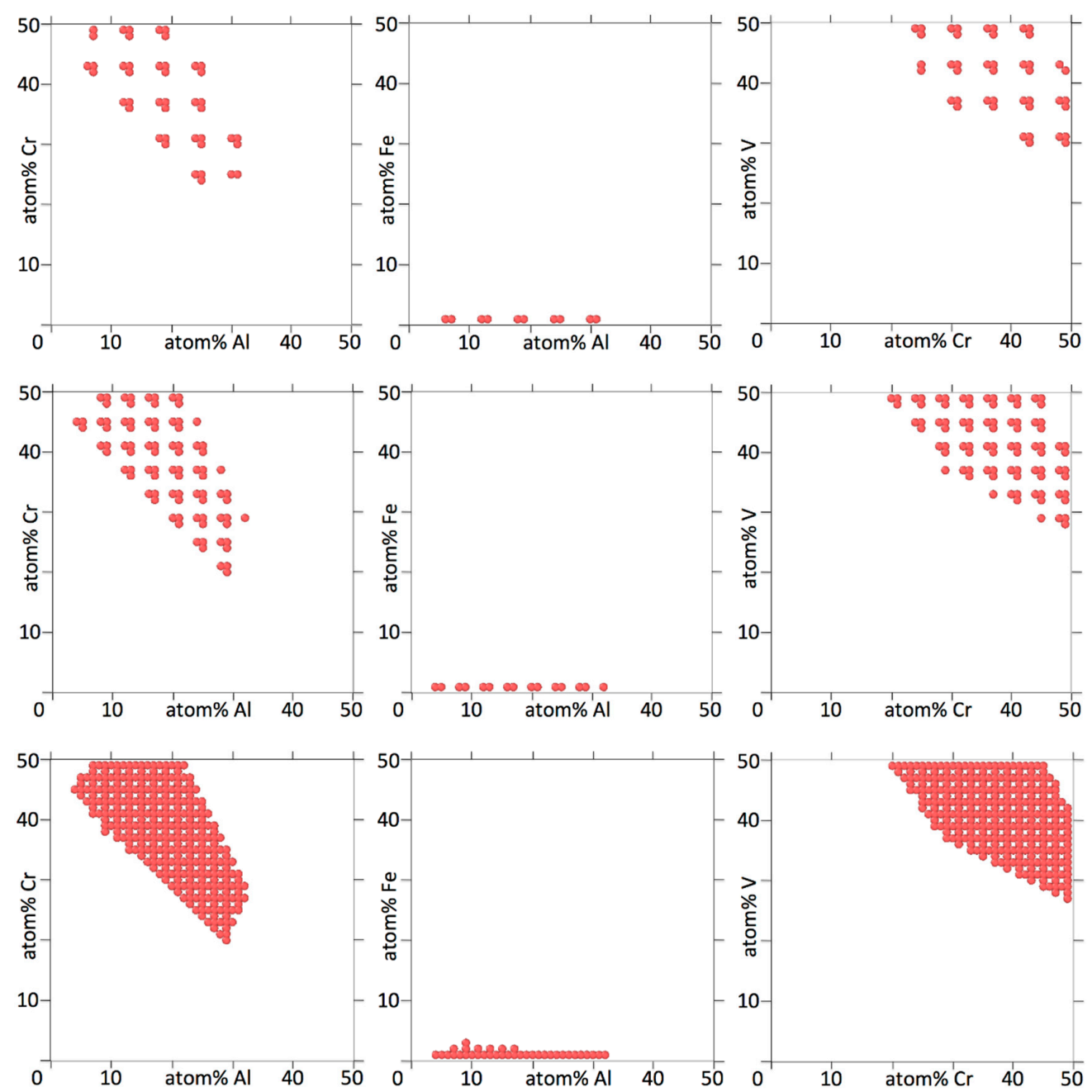

Figure 2. Two-dimensional projections for $\mathrm{Al}_{\mathrm{a}} \mathrm{Cr}_{\mathrm{b}} \mathrm{Fe}_{\mathrm{c}} \mathrm{Ti}_{\mathrm{d}} \mathrm{V}_{1-\mathrm{a}-\mathrm{b}-\mathrm{c}-\mathrm{d}}$, showing at which concentrations for two elements the alloy forms a bcc HEA at $800 \mathrm{~K}$. Three concentration dimensions are flattened out to arrive at the two-dimensional projection. The concentrations of the three elements not shown can be any one or multiple combinations, i.e., a circle indicates that for the corresponding concentration of the two elements shown, there is at least one and in most cases there are many combinations of concentrations of the other three elements for which the alloy forms a HEA at $800 \mathrm{~K}$. The concentration increments in the top, middle and bottom figures are 6,4 and $2 \%$, respectively. 

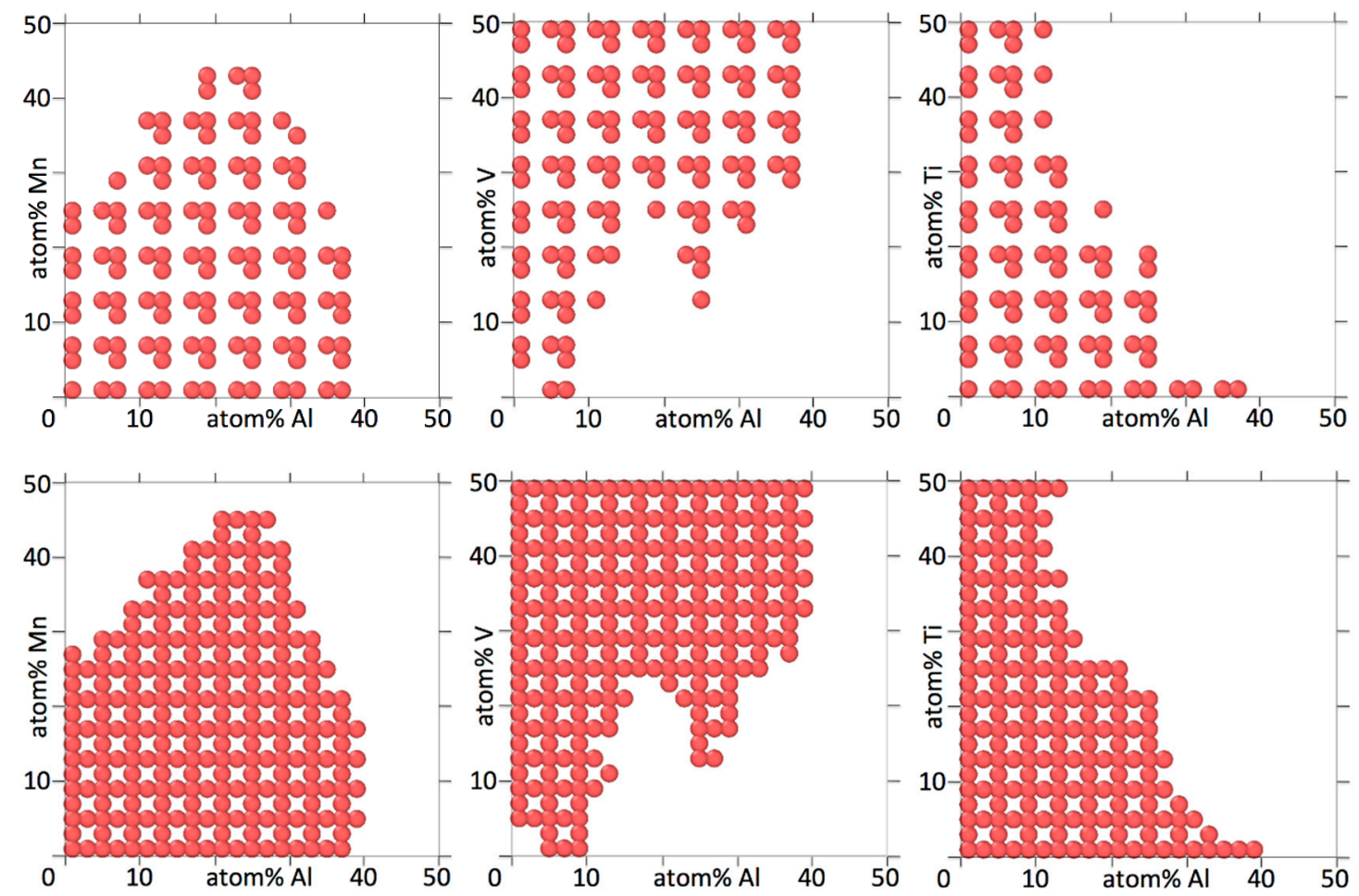

Figure 3. Two-dimensional projections for $\mathrm{Al}_{\mathrm{a}} \mathrm{Cr}_{\mathrm{b}} \mathrm{Mn}_{\mathrm{c}} \mathrm{Nb}_{\mathrm{d}} \mathrm{Ti}_{\mathrm{e}} \mathrm{V}_{1 \text {-a-b-c-d-e, showing at which }}$ concentrations for two elements the alloy forms a bcc HEA at $800 \mathrm{~K}$. Four concentration dimensions are flattened out to arrive at the two-dimensional projection. The concentrations of the four elements not shown are as explained in the caption of Figure 2. The concentration increments in the top and bottom figures are 6 and $4 \%$, respectively.

In the small sampling of projections in Figures 2 and 3 there are only single islands of HEA stability, there are no small separate islands. Also, the islands are solid without holes in them. Generally the size of the islands is many times larger than the concentration spacing. The concentration spacing therefore only influences the outer edges of the islands. At a coarser spacing, some detail of the shapes of outer edges of the islands is lost, but the overall shapes of the islands are preserved. This means that for the cases shown, a relatively modest number of compositions on a coarse grid in composition space already provide most information about islands of low temperature HEA stability.

\subsection{The Different Roles of Alloying Elements}

Figures 4-7 show binary projections as in Figures 2 and 3 for all possible binary combinations in our alloys.
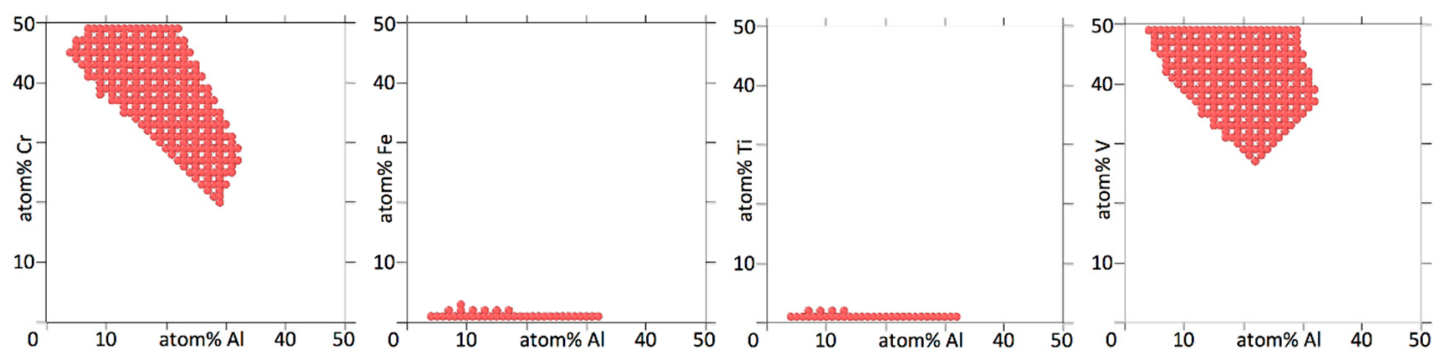

Figure 4. Cont. 

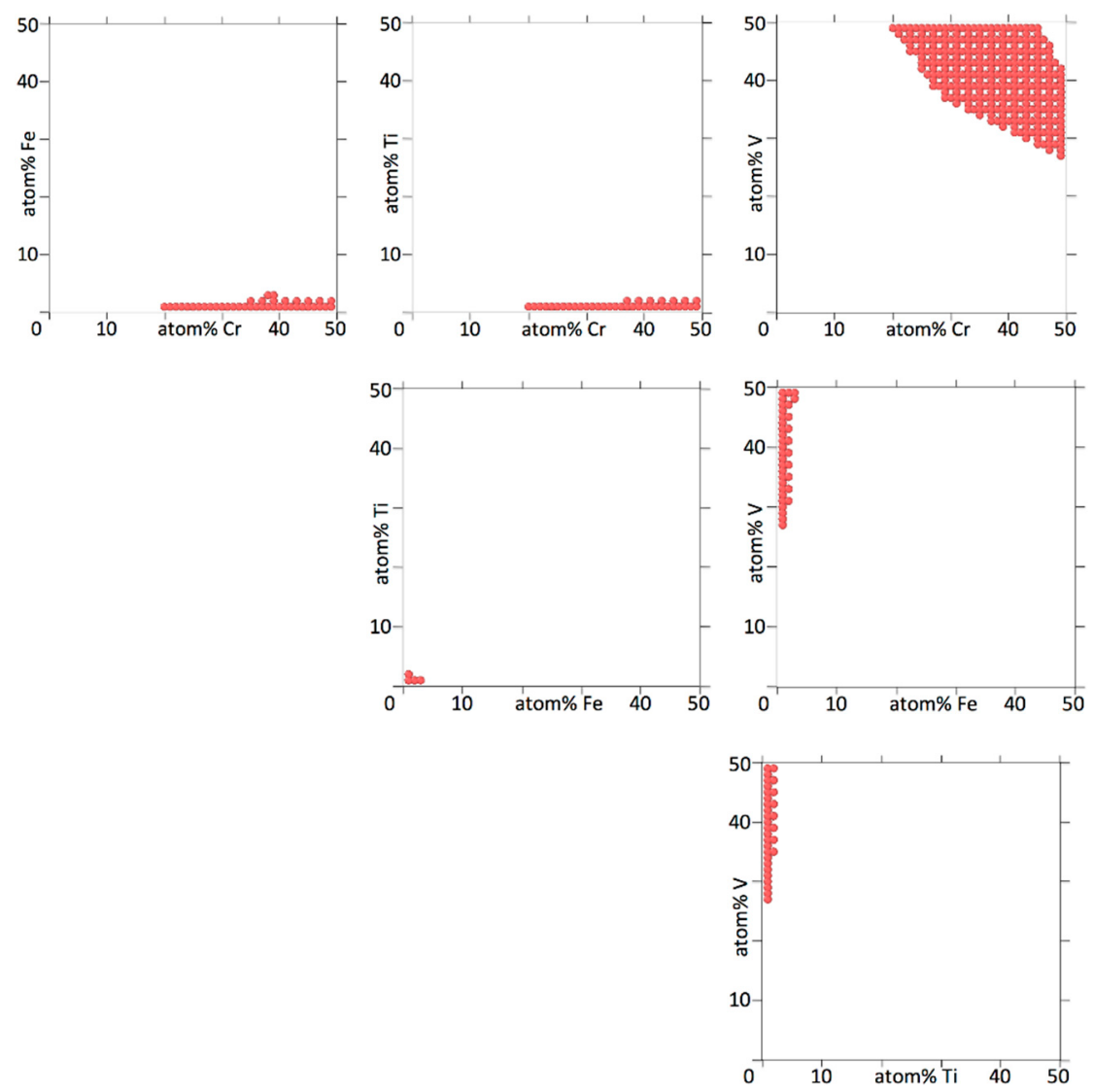

Figure 4. Two-dimensional projections for $\mathrm{Al}_{\mathrm{a}} \mathrm{Cr}_{\mathrm{b}} \mathrm{Fe}_{\mathrm{c}} \mathrm{Ti}_{\mathrm{d}} \mathrm{V}_{1-\mathrm{a}-\mathrm{b}-\mathrm{c}-\mathrm{d}}$, showing at which concentrations for two elements the alloy forms a bcc HEA at $800 \mathrm{~K}$. Three concentration dimensions are flattened out to arrive at the two-dimensional projection. The concentrations of the three elements not shown are as explained in the caption of Figure 2. The concentration increments are $2 \%$.
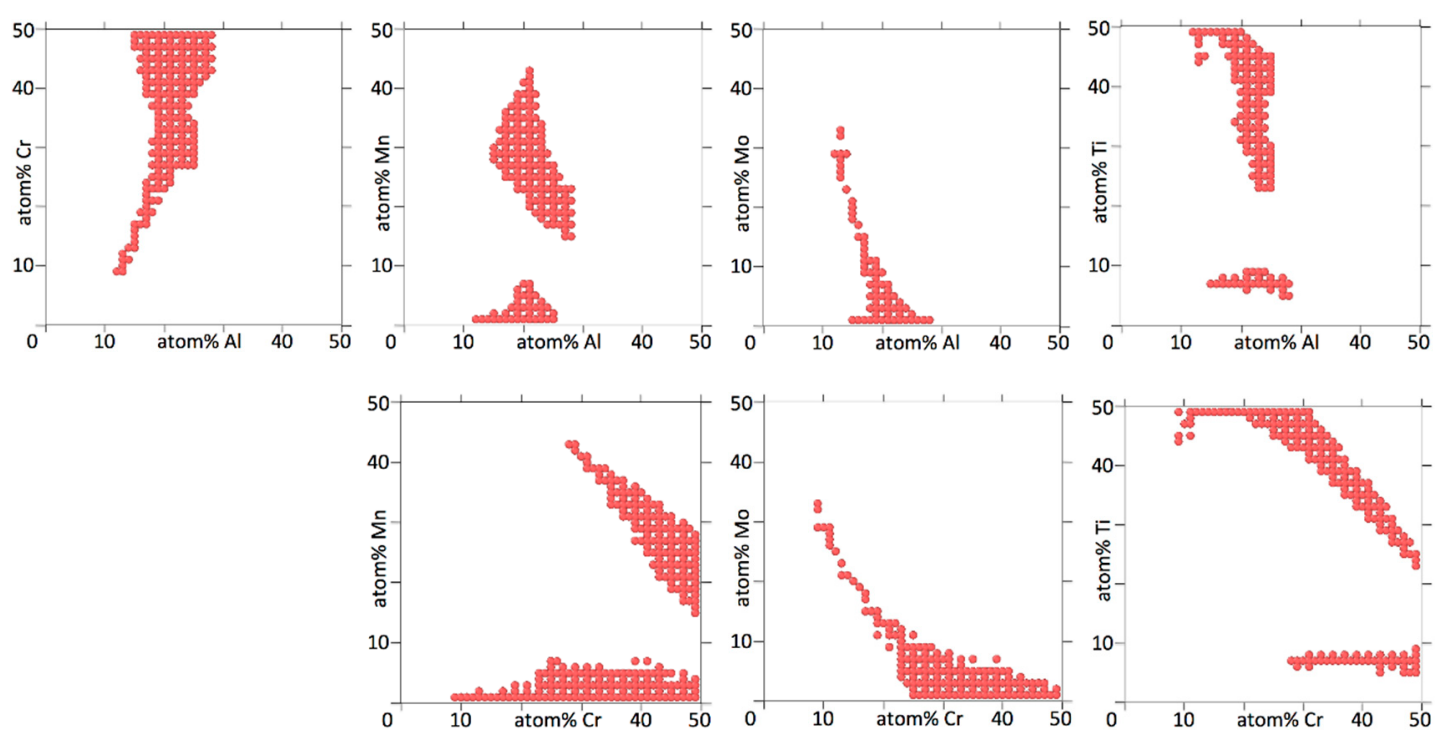

Figure 5. Cont. 

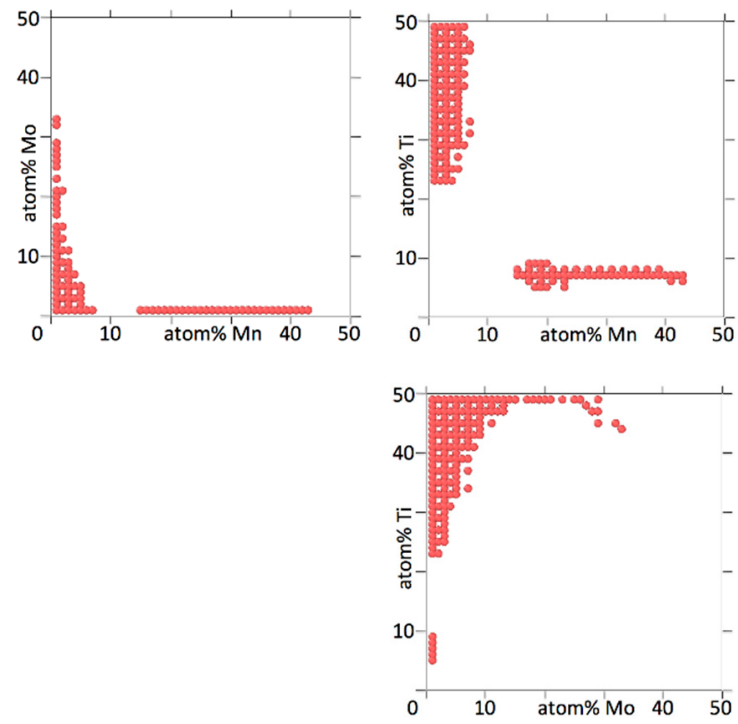

Figure 5. Two-dimensional projections for $\mathrm{Al}_{\mathrm{a}} \mathrm{Cr}_{\mathrm{b}} \mathrm{Mn}_{\mathrm{c}} \mathrm{Mo}_{\mathrm{d}} \mathrm{Ti}_{1-\mathrm{a}-\mathrm{b}-\mathrm{c}-\mathrm{d}}$, showing at which concentrations for two elements the alloy forms a bcc HEA at $800 \mathrm{~K}$. Three concentration dimensions are flattened out to arrive at the two-dimensional projection. The concentrations of the three elements not shown are as explained in the caption of Figure 2. The concentration increments are $2 \%$.
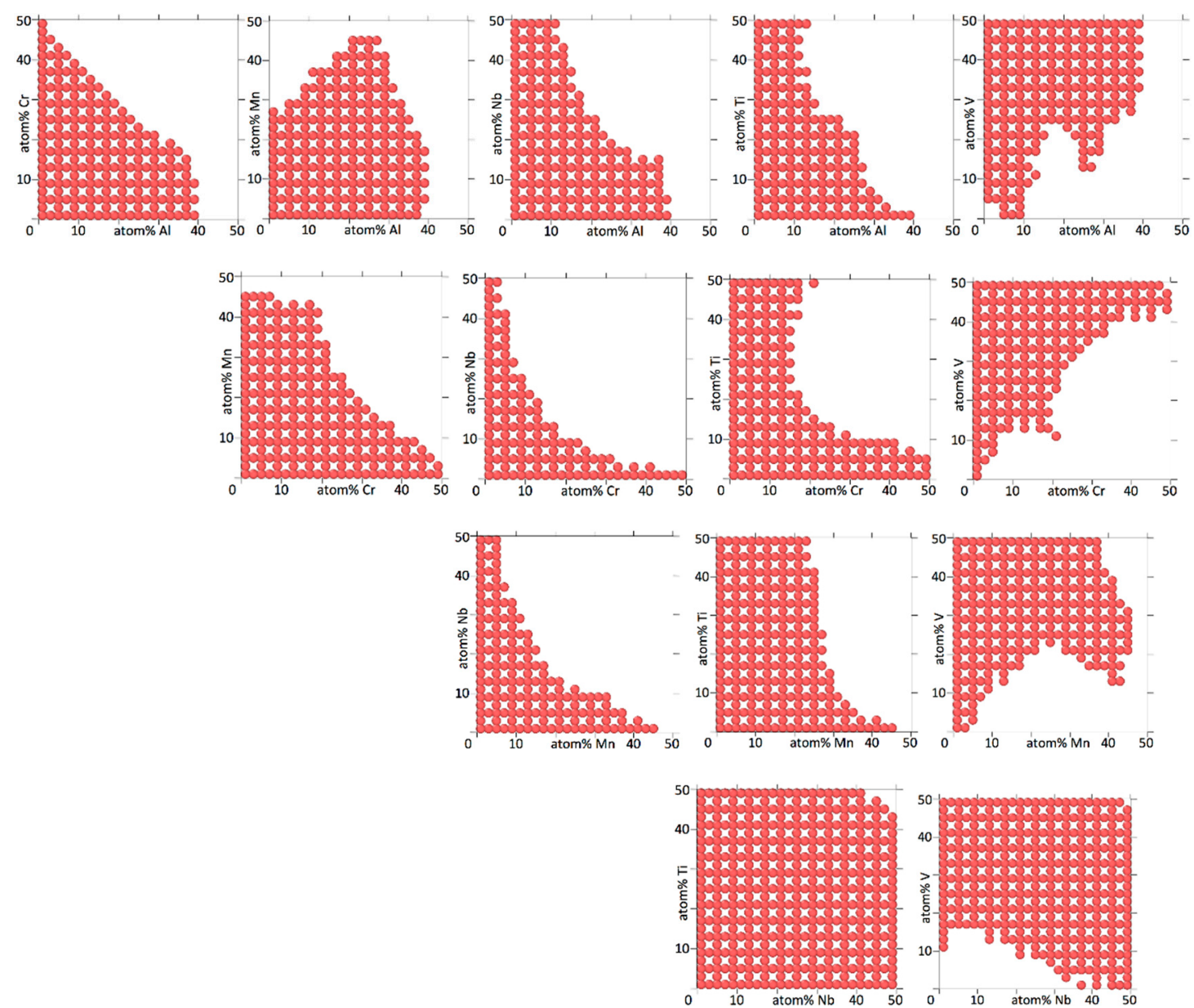

Figure 6. Cont. 


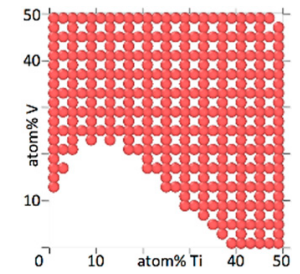

Figure 6. Two-dimensional projections for $\mathrm{Al}_{\mathrm{a}} \mathrm{Cr}_{\mathrm{b}} \mathrm{Mn}_{\mathrm{c}} \mathrm{Nb}_{\mathrm{d}} \mathrm{Ti}_{\mathrm{e}} \mathrm{V}_{1 \text {-a-b-c-d-e, showing at which }}$ concentrations for two elements the alloy forms a bcc HEA at $800 \mathrm{~K}$. Four concentration dimensions are flattened out to arrive at the two-dimensional projection. The concentrations of the four elements not shown are as explained in the caption of Figure 2. The concentration increments are $4 \%$.
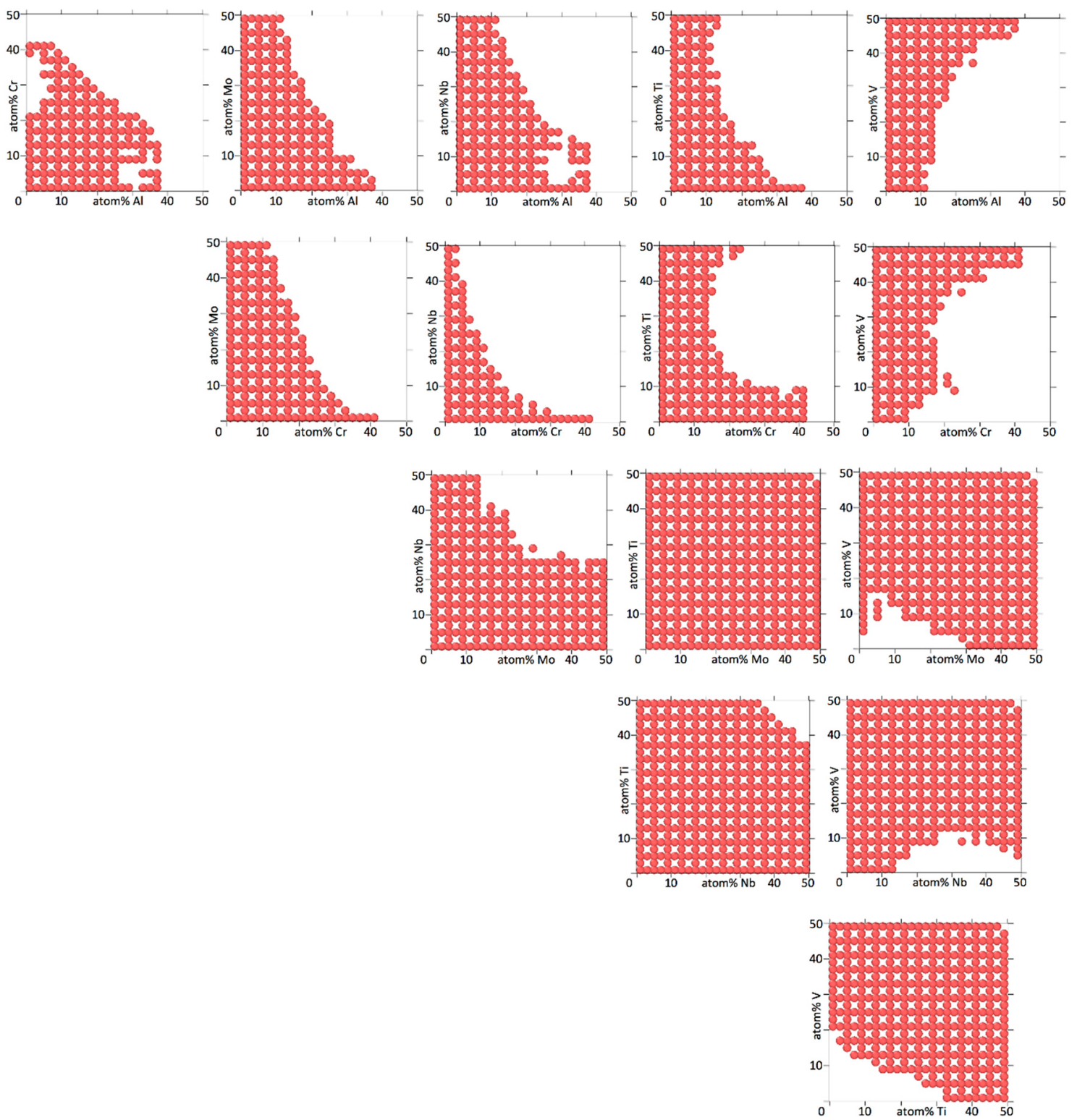

Figure 7. Two-dimensional projections for $\mathrm{Al}_{\mathrm{a}} \mathrm{Cr}_{\mathrm{b}} \mathrm{Mo}_{\mathrm{c}} \mathrm{Nb}_{\mathrm{d}} \mathrm{Ti}_{\mathrm{e}} \mathrm{V}_{1 \text {-a-b-c-d-e, showing at which }}$ concentrations for two elements the alloy forms a bcc HEA at $800 \mathrm{~K}$. Four concentration dimensions are flattened out to arrive at the two-dimensional projection. The concentrations of the four elements not shown are as explained in the caption of Figure 2. The concentration increments are $4 \%$.

In interpreting Figures 4-7, it is worth pointing out that a lot of information is left out of the two-dimensional projections. What appears to be a single island may in fact consists of several 
separate islands in the dimension perpendicular to the projection (which contains all the information of the other elements than the two being shown), that overlap into a single island when shown as a two-dimensional projection.

Figures 4-7 show that the various elements in the four alloys play distinct roles. On the one hand, Fe and Ti in AlCrFeTiV hardly participate in forming a HEA. Single disordered bcc phases in $\mathrm{AlCrFeTiV}$ can form, but they are essentially ternary alloys, without Fe or Ti. On the other hand, Mo and $\mathrm{Ti}$ in $\mathrm{AlCrMoNbTiV}$ can form HEAs with the other elements at any combination of concentrations. In between these two extremes, a variety of other behaviors can be observed. HEA islands that cover part of the two-element projections may extend mutually over the full 0-50\% range for both elements or over the full range for one element but part of the range for the other, or over part of the range for both elements. A minimum concentration of the two elements can be required, indicated by a lack of circles around the origin, such as for TiV in AlCrMnNbTiV, see Figure 6. The HEA island may be formed under an inversely proportional line, such as for $\mathrm{CrNb}$ in $\mathrm{AlCrMnNbTiV}$, see Figure 6 . The maximum percentage of one element as a function of the other may not follow a monotonous line, there may be minima and maxima such as for AlMn and AlV in AlCrMnNbTiV, see Figure 6. $\mathrm{V}$ in $\mathrm{AlCrMnNbTiV}$ in particular gives many minima and maxima in the two-dimensional projections in Figure 6. There may even be an archipelago of separate islands of stability, as is the case with the thin, stretched-out islands for AlCrMnMoTi, see Figure 5. Islands are seen to feature a great variety of shapes, including bays, peninsular outcroppings and satellite islands, see $\mathrm{AlCr}, \mathrm{AlNb}$ and $\mathrm{CrV}$ in $\mathrm{AlCrMoNbTiV}$, Figure 7. Contrary to the results of convergence testing in Section 3.2, some of these features would be lost if the calculations were carried out on a coarser grid.

Overall, the two six element alloys appear to be more promising candidates for forming low temperature HEAs than the two five element alloys. For AlCrMnNbTiV and AlCrMoNbTiV 17,830 $(3.8 \%)$ and $17,289(3.7 \%)$ out of 473,382 compositions sampled were single phase HEAs at $800 \mathrm{~K}$. For AlCrFeTiV and AlCrMnMoTi only $356(0.041 \%)$ and $785(0.091 \%)$ out of 862,750 compositions sampled were single phase HEAs at $800 \mathrm{~K}$. In Figures 6 and 7 on average $64 \%$ and $67 \%$ of the grid points of the two-dimensional projections for $\mathrm{AlCrMnNbTiV}$ and $\mathrm{AlCrMoNbTiV}$ have circles on them, while in Figures 4 and 5 these percentages are only $6.8 \%$ and $9.4 \%$ for AlCrFeTiV and AlCrMnMoTi. The supplementary material contains the list of compositions calculated and for each composition, whether that composition is a HEA at $800 \mathrm{~K}$ or not and what the phases and phase fractions are at $800 \mathrm{~K}$ for the four alloy systems.

\subsection{Temperature Dependence of HEA Stability}

Figure 8 shows the fraction of alloy compositions for which a HEA is formed as a function of temperature.

Figure 8 shows that both six element alloys are strong HEA formers, with $4 \%$ of compositions being HEAs at $800 \mathrm{~K}$ and the HEA fraction of fully solid alloys reaching over $90 \%$ at $2000 \mathrm{~K}$. The much lower melting temperature of Mn (1519 K) compared to Mo (2896 K) increases the fraction of (partly) molten alloys at $2000 \mathrm{~K}$ but it does not greatly increase the onset of melting, since melting is likely to occur first for compositions rich in low-melting metals like Al. Also, alloys with little Mn or Mo are almost the same. In contrast to the six element alloys, AlCrFeTiV obviously has poor HEA forming qualities. AlCrMnMoTi is in between the six element alloys and AlCrFeTiV, with a very low fraction of HEAs at $800 \mathrm{~K}$, but the fraction rapidly increases with temperature, surpassing that of the six element alloys and reaching $100 \%$ at $1750 \mathrm{~K}$. Figure 9 shows the average concentrations of individual elements in HEAs as a function of temperature. 


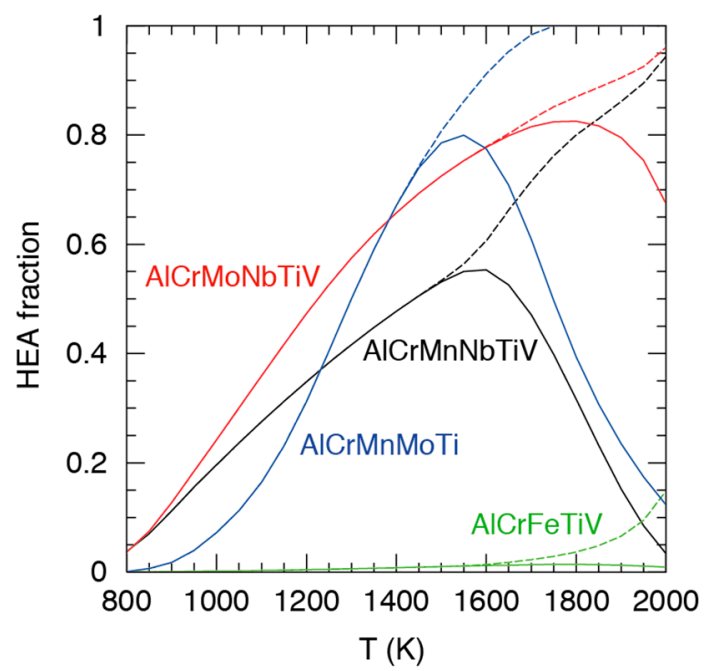

Figure 8. Fractions of alloy compositions for which a HEA is formed, as a function of temperature. Solid curves represent the number of HEAs as a fraction of all compositions, including those that are (partly) molten. Dashed curves represent the number of HEAs as a fraction of compositions for which the alloys are still completely solid.
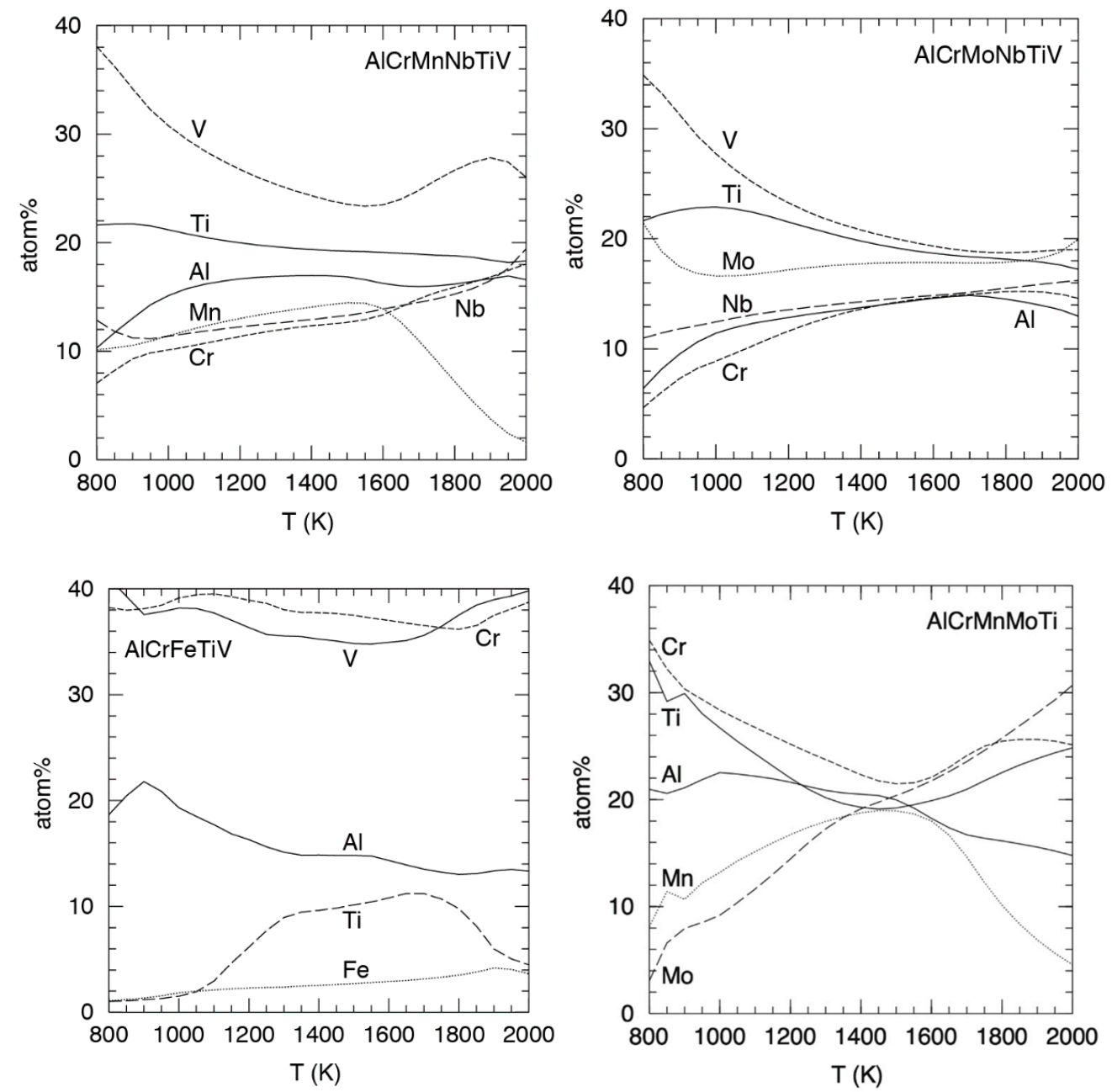

Figure 9. Average atom percentages of elements as a function of temperature, averaged over those compositions that form HEAs. 
It is perhaps surprising to observe that in $\mathrm{AlCrMnNbTiV}$ and $\mathrm{AlCrMnMoTi}$, Mn is the element that is the most reduced in concentration at higher temperatures, while pure Mn has a far higher melting temperature $(1519 \mathrm{~K})$ than pure $\mathrm{Al}(933 \mathrm{~K})$. At present we are not able to explain this. For AlCrFeTiV the average composition shown in Figure 9 does not actually lie inside a HEA island for most of the temperature range. For the other three alloys the average concentrations shown in Figure 9 do lie inside HEA islands for all but a few of the lowest temperatures.

It should be noted that our calculations assume thermodynamic equilibrium and therefore homogenous phases. During solidification usually concentration gradients in the solid state develop so that our results may deviate from experimentally prepared materials.

\subsection{HEA Island Centers}

The center of a HEA island is here defined as the HEA composition that is furthest removed from any composition that is not a HEA. The distance between the island center and the closest non-HEA composition defines a body around the island center that contains a subset of the compositions that form the island. The size of the body indicates how much the concentrations of any element(s) can be varied from the island center while the alloy still remains a HEA. The island center-closest non-HEA distance can be calculated as the Euclidian distance (in which case the body is a high-dimensional spheroid) or Manhattan distance (in which case the body is a high-dimensional polyhedron, with a larger volume than the spheroid). Since we allow concentrations up to $50 \%$, an island center may be close to $50 \%$ for one or two elements. Therefore it needs to be decided what to do with compositions on grid points on or outside the $50 \%$ boundary, for which there is no data. On the one hand, since the vast majority of compositions are not HEAs, it could be assumed that any composition on or outside the $50 \%$ boundary is not a HEA. This means that the sphere or polyhedron around the center must lie entirely within the $50 \%$ boundaries. On the other hand, if there is a part of an island of HEA stability bordering the $50 \%$ boundary, it is reasonable to assume that the island would not end abruptly at the $50 \%$ boundary but extend some distance beyond it as well. Therefore it could be argued that the center of the island needs to lie within the $50 \%$ boundary, but that part of the sphere or polyhedron may lie outside it. These two scenarios represent extremes for the smallest and biggest possible spheres / polyhedra and specific cases will usually lie somewhere in between. We shall present results for both scenarios, where all compositions at or beyond $50 \%$ are assumed to be non-HEAs ('boundary_on') or where compositions at or beyond 50\% are assumed to be HEAs ('boundary_off'). For the former scenario, non-HEA composition data points are added (i.e., defined, not calculated with TC) for all compositions where one or two elements have a 50\% concentration. As an example, Table 2 shows the island center(s) composition for AlCrMnNbTiV.

The alternative, equally valid island center compositions indicated by the asterisks in Table 2 are compositions like $3,1,1,25,21,49 \%$ or $1,1,3,21,25,49 \% \mathrm{Al}, \mathrm{Cr}, \mathrm{Mn}, \mathrm{Nb}, \mathrm{Ti}, \mathrm{V}$.

Under boundary_on condition, the Euclidian distance between the island center and the nearest non-HEA compositions is $\sqrt{ } 102=10.1 \%$. This is only a few times the concentration increment, hence the figure of $10.1 \%$ is not very precise. However, it does mean that the alloy will remain a HEA under limited composition changes. For example, if any one element is changed $9 \%$ in one direction and four other elements are changed $2 \%$ in the opposite direction and one element is changed $1 \%$ in the opposite direction, the resulting alloy should still be a HEA. Table 3 shows the island center compositions for all four of our HEAs and the distances to the closest non-HEA compositions.

As in Figures 4-7, the compositions in Table 3 show that the six element alloys are much better HEA formers than the five element alloys at $800 \mathrm{~K}$. The island radii for the five element alloys are so small that there are not really any HEA islands, just a few isolated HEA compositions, possibly with a very small number of their closest neighbor compositions. Finally in this section we show how HEA islands grow with temperature. Figure 10 shows the radii as a function of temperature for $\mathrm{AlCrMnNbTiV}$ and AlCrFeTiV. 
Table 2. HEA island center composition for $\mathrm{AlCrMnNbTiV}$, determined with different distance and boundary criteria at $800 \mathrm{~K}$. Also shown are the five non-HEA compositions closest to the island center. The elements concentration spacing is $4 \%$. An asterix behind an island center composition indicates there are other island center compositions nearby that have an equally long distance to a nearest non-HEA composition.

\begin{tabular}{|c|c|c|c|c|}
\hline & \multicolumn{4}{|c|}{ Distance and Boundary Criteria } \\
\hline & \multicolumn{2}{|c|}{ Euclidean Distance } & \multicolumn{2}{|c|}{ Manhattan distance } \\
\hline & Boundary_on & Boundary_off & Boundary_on & Boundary_off \\
\hline & $\% \mathrm{Al} \mathrm{Cr} \mathrm{Mn} \mathrm{Nb} \mathrm{T}$ & & & \\
\hline $\begin{array}{l}\text { island } \\
\text { centre(s) }\end{array}$ & $\begin{array}{llll}1 & 1 & 1253141\end{array}$ & $\begin{array}{llll}1 & 1 & 1232549\end{array}$ & $\begin{array}{lllr}1 & 3 & 1 & 213737^{*} \\
1 & 1 & 13 & 53941^{*}\end{array}$ & 131212549 * \\
\hline $\begin{array}{l}\text { 1st nearest } \\
\text { non-HEA }\end{array}$ & $\begin{array}{l}0 \quad 0 \quad 0222850 \\
10.1 \% \text { from center }\end{array}$ & $\begin{array}{l}11 \quad 1 \quad 1172545 \\
12.3 \% \text { from center }\end{array}$ & $\begin{array}{l}111 \quad 1212937 \\
7 \quad 1 \quad 5 \quad 5 \quad 4141 \\
16 \% \text { from center }\end{array}$ & $\begin{array}{l}1111251349 \\
24 \% \text { from center }\end{array}$ \\
\hline $\begin{array}{l}\text { 2nd nearest } \\
\text { non-HEA }\end{array}$ & $\begin{array}{l}0 \quad 0 \quad 0212950 \\
10.2 \% \text { from center }\end{array}$ & $\begin{array}{lcc}9 & 1 & 11172943 \\
12.3 \% & \text { from center }\end{array}$ & $\begin{array}{l}1111213333 \\
7 \quad 1 \quad 9 \quad 14141 \\
16 \% \text { from center }\end{array}$ & $\begin{array}{l}111 \quad 1251745 \\
24 \% \text { from center }\end{array}$ \\
\hline $\begin{array}{l}\text { 3rd nearest } \\
\text { non-HEA }\end{array}$ & $\begin{array}{l}0 \quad 0 \quad 0232750 \\
10.2 \% \text { from center }\end{array}$ & 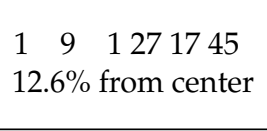 & 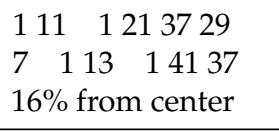 & $\begin{array}{l}111 \quad 1252141 \\
24 \% \text { from center }\end{array}$ \\
\hline $\begin{array}{l}\text { 4th nearest } \\
\text { non-HEA }\end{array}$ & $\begin{array}{lcc}0 & 0 & 1212850 \\
10.4 \% & \text { from center }\end{array}$ & $\begin{array}{lcc}1 & 9 & 1272141 \\
12.6 \% & \text { from center }\end{array}$ & 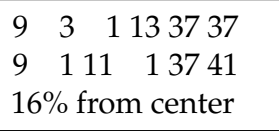 & $\begin{array}{l}1111252141 \\
24 \% \text { from center }\end{array}$ \\
\hline $\begin{array}{l}\text { 5th nearest } \\
\text { non-HEA }\end{array}$ & $\begin{array}{lcc}0 & 0 & 1222750 \\
10.4 \% & \text { from center }\end{array}$ & $\begin{array}{l}9 \quad 1 \quad 1152945 \\
12.6 \% \text { from center }\end{array}$ & 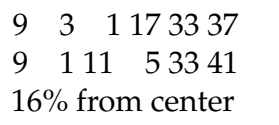 & $\begin{array}{l}191271349 \\
24 \% \text { from center }\end{array}$ \\
\hline
\end{tabular}

Unsurprisingly, the island radius pattern for $\mathrm{AlCrMnNbTiV}$ in Figure 10 is rather similar to the pattern of the AlCrMnNbTiV HEA fraction shown for AlCrMnNbTiV in Figure 8.
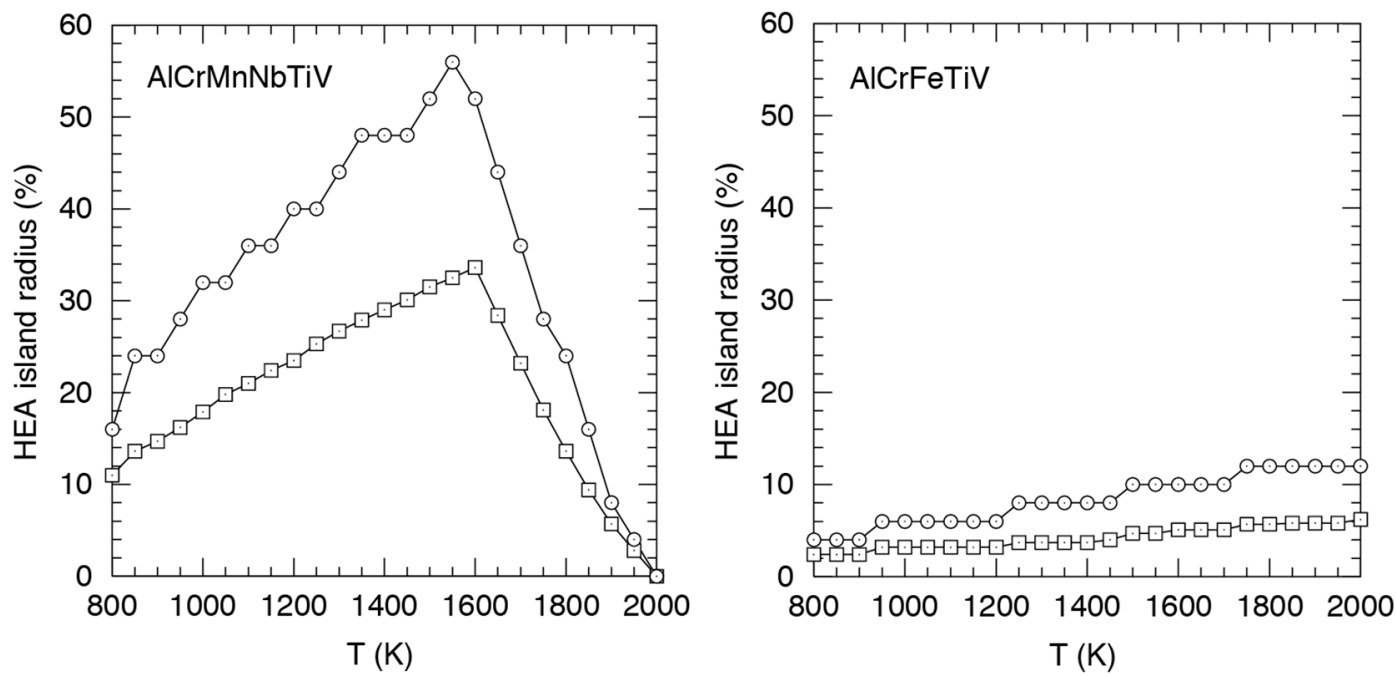

Figure 10. Euclidian (squares) and Manhattan (circles) radii of HEA islands around $\mathrm{Al}_{1} \mathrm{Cr}_{1} \mathrm{Mn}_{1} \mathrm{Nb}_{25} \mathrm{Ti}_{31} \mathrm{~V}_{41}$ and $\mathrm{Al}_{11} \mathrm{Cr}_{43} \mathrm{Fe}_{1} \mathrm{Ti}_{1} \mathrm{~V}_{44}$ under boundary_off condition. Radii are here defined as the distances between the island center and the nearest non-HEA composition. Only compositions less than a radius away from the island center are guaranteed to be HEAs. 
Table 3. HEA island center(s) compositions, determined with different distance and boundary criteria at $800 \mathrm{~K}$. Below each composition is the distance to the nearest non-HEA composition. The elements concentration spacing is $4 \%$ for the six element alloys and $2 \%$ for the five element alloys. An asterix behind an island center composition indicates there are other island center compositions nearby that have an equally long distance to a nearest non-HEA composition.

\begin{tabular}{|c|c|c|c|c|}
\hline & \multicolumn{4}{|c|}{ Island Center(s) and Distance to Nearest Non-HEA Composition } \\
\hline & \multicolumn{2}{|c|}{ Euclidean Distance } & \multicolumn{2}{|c|}{ Manhattan Distance } \\
\hline & Boundary_on & Boundary_off & Boundary_on & Boundary_off \\
\hline Alloy & \multicolumn{4}{|c|}{$\%$ Elements } \\
\hline AlCrMnNbTiV & $\begin{array}{l}111253141 \\
10.1 \%\end{array}$ & $\begin{array}{l}1 \quad 1 \quad 1232549 \\
12.3 \%\end{array}$ & $\begin{array}{llrr}1 & 3 & 1 & 213737 \text { * } \\
1 & 1 & 13 & 53941^{*} \\
16 \% & \end{array}$ & $\begin{array}{l}13 \\
24 \%\end{array}$ \\
\hline AlCrMoNbTiV & $\begin{array}{l}1137 \quad 12139 * \\
10.2 \%\end{array}$ & $\begin{array}{lll}1 & 137 & 11347^{*} \\
11.3 \% & \end{array}$ & $\begin{array}{l}113912137 \text { * } \\
20 \%\end{array}$ & $\begin{array}{l}113511349 * \\
24 \%\end{array}$ \\
\hline $\mathrm{AlCrFeTiV}$ & $\begin{array}{lll}1143 & 1 & 144 \\
2.4 \% & & \end{array}$ & $\begin{array}{lll}1143 & 1 & 144 \\
2.4 \% & & \end{array}$ & $\begin{array}{lll}1143 & 1 & 144 \\
4 \% & & \end{array}$ & $\begin{array}{lll}1143 & 1 & 144^{*} \\
4 \% & & \end{array}$ \\
\hline AlCrMnMoTi & $\begin{array}{lll}2233 & 1 & 143 \\
3.7 \% & & \end{array}$ & $\begin{array}{lll}2233 & 1 & 143 * \\
3.7 \% & & \end{array}$ & $\begin{array}{lll}2233 & 1 & 143 * \\
6 \% & & \end{array}$ & $\begin{array}{lll}2233 & 1 & 143 \\
6 \% & & \end{array}$ \\
\hline
\end{tabular}

\subsection{HEA Compositions with Minimum Concentration Constraints}

The compositions in Table 3 are all essentially ternary alloys, meaning they are not really conventional HEAs. For the six element alloys, the elements mostly absent from the island center compositions include $\mathrm{Al}$ and $\mathrm{Cr}$. While oxidation resistance depends on more than just having significant amounts of $\mathrm{Al}$ and/or Cr present in alloys, their presence is an important enabling factor for oxidation resistance. We repeated our search for HEA islands of maximum size, but now under the condition that minimum amounts of $\mathrm{Al}$ and/or $\mathrm{Cr}$ are present in the alloys or that four or more elements must be present in a concentration equal or greater than $10 \%$. Tables 4 and 5 show HEA island center compositions and sizes determined under these constraints.

Table 4. HEA island center(s) compositions, determined with different distance and boundary criteria at $800 \mathrm{~K}$, under the constraint of having minimum amounts of $\mathrm{Al}$ and/or $\mathrm{Cr}$ present. Below each composition is the distance to the nearest non-HEA composition. The elements concentration spacing is $4 \%$ for the six element alloys and $2 \%$ for the five element alloys. An asterix behind an island center composition indicates there are other island center compositions nearby that have an equally long distance to a nearest non-HEA composition.

\begin{tabular}{|c|c|c|c|c|}
\hline & \multicolumn{4}{|c|}{ Island Center(s) and Distance to Nearest Non-HEA Composition } \\
\hline & \multicolumn{2}{|c|}{ Euclidean Distance } & \multicolumn{2}{|c|}{ Manhattan Distance } \\
\hline & Boundary_on & Boundary_off & Boundary_on & Boundary_off \\
\hline Alloy, Constraint & $\%$ Al Cr Mn Nb Ti V & & & \\
\hline $\begin{array}{l}\mathrm{AlCrMnNbTiV} \\
\mathrm{Al} \geq 15 \%\end{array}$ & $\begin{array}{lrll}25 & 725 & 1 & 141 \\
21 & 721 & 1 & 941 \\
7.5 \% & & \end{array}$ & $\begin{array}{llll}25 & 123 & 1 & 149 \\
9.8 \% & & & \end{array}$ & $\begin{array}{l}25721 \quad 1 \quad 541 \text { * } \\
12 \%\end{array}$ & $\begin{array}{l}21521 \quad 1 \quad 547^{*} \\
16 \%\end{array}$ \\
\hline $\begin{array}{l}\mathrm{AlCrMnNbTiV} \\
\mathrm{Cr} \geq 15 \%\end{array}$ & $\begin{array}{l}171517 \quad 1 \quad 941 \\
5.7 \%\end{array}$ & $\begin{array}{l}111713 \quad 1 \quad 949 * \\
6.3 \%\end{array}$ & 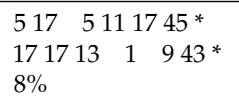 & $\begin{array}{l}111713 \quad 1 \quad 949 \text { * } \\
12 \%\end{array}$ \\
\hline $\begin{array}{l}\mathrm{AlCrMnNbTiV} \\
\mathrm{Al}+\mathrm{Cr} \geq 15 \%\end{array}$ & $\begin{array}{lllll}25 & 7225 & 1 & 141 \\
21 & 7221 & 1 & 941 \\
7.5 \% & & & \end{array}$ & $\begin{array}{l}25 \quad 123 \quad 1 \quad 149 \\
9.8 \%\end{array}$ & 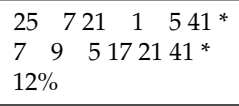 & 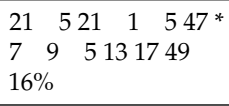 \\
\hline $\begin{array}{l}\mathrm{AlCrMoNbTiV} \\
\mathrm{Al} \geq 15 \%\end{array}$ & 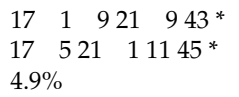 & $\begin{array}{l}15 \quad 1 \quad 521 \quad 949 * \\
6.3 \%\end{array}$ & 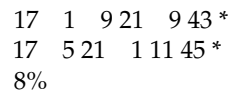 & $\begin{array}{l}151 \\
12 \%\end{array}$ \\
\hline
\end{tabular}


Table 4. Cont.

\begin{tabular}{|c|c|c|c|c|c|c|c|c|c|}
\hline & \multicolumn{9}{|c|}{ Island Center(s) and Distance to Nearest Non-HEA Composition } \\
\hline & \multicolumn{5}{|c|}{ Euclidean Distance } & \multicolumn{4}{|c|}{ Manhattan Distance } \\
\hline & \multicolumn{2}{|c|}{ Boundary_on } & \multicolumn{3}{|c|}{ Boundary_off } & \multicolumn{2}{|c|}{ Boundary_on } & \multicolumn{2}{|c|}{ Boundary_off } \\
\hline Alloy, Constraint & $\% \mathrm{Al} \mathrm{Cr}$ & $\mathrm{Mn} \mathrm{Nb} \mathrm{Ti}$ & & & & & & & \\
\hline $\begin{array}{l}\mathrm{AlCrMoNbTiV} \\
\mathrm{Cr} \geq 15 \%\end{array}$ & $\begin{array}{l}91521 \\
4.9 \%\end{array}$ & 11341 * & $\begin{array}{l}1517 \\
131711 \\
4.9 \%\end{array}$ & $\begin{array}{lr}1 & 5 \\
1 & 1 \\
& \end{array}$ & $\begin{array}{l}51349 \\
1 \quad 949 *\end{array}$ & $\begin{array}{l}91521 \\
8 \%\end{array}$ & $11341 *$ & $\begin{array}{llll}15 & 17 & 1 \\
13 & 17 & 11 & 1 \\
8 \% & & & \\
\end{array}$ & $\begin{array}{c}51349 \\
1 \quad 949 \text { * }\end{array}$ \\
\hline $\begin{array}{l}\mathrm{AlCrMoNbTiV} \\
\mathrm{Al}+\mathrm{Cr} \geq 15 \%\end{array}$ & $\begin{array}{l}9729 \\
6.3 \%\end{array}$ & $11341 *$ & $\begin{array}{l}11 \quad 52 \\
7.5 \%\end{array}$ & 251 & $1949 *$ & $\begin{array}{l}9729 \\
12 \%\end{array}$ & 11341 * & $\begin{array}{l}11525 \\
16 \%\end{array}$ & 1949 * \\
\hline $\begin{array}{l}\mathrm{AlCrFeTiV} \\
\mathrm{Al} \geq 15 \%\end{array}$ & $\begin{array}{ll}2336 & 1 \\
1.4 \% & \\
\end{array}$ & 139 * & $\begin{array}{l}2336 \\
1.4 \% \\
\end{array}$ & 11 & $139 *$ & $\begin{array}{ll}2336 & 1 \\
2 \% & \\
\end{array}$ & 1139 * & $\begin{array}{ll}2336 & 1 \\
2 \% & \\
\end{array}$ & $139 *$ \\
\hline $\begin{array}{l}\mathrm{AlCrFeTiV} \\
\mathrm{Cr} \geq 15 \%\end{array}$ & $\begin{array}{ll}1143 & 1 \\
2.4 \% & \\
\end{array}$ & 144 * & $\begin{array}{l}1143 \\
2.4 \% \\
\end{array}$ & 11 & $144^{*}$ & $\begin{array}{ll}1143 & 1 \\
4 \% & \\
\end{array}$ & 1144 * & $\begin{array}{ll}1143 & 1 \\
4 \% & \\
\end{array}$ & $144 *$ \\
\hline $\begin{array}{l}\mathrm{AlCrFeTiV} \\
\mathrm{Al}+\mathrm{Cr} \geq 15 \%\end{array}$ & $\begin{array}{ll}1143 & 1 \\
2.4 \% & \\
\end{array}$ & $1144^{*}$ & $\begin{array}{l}1143 \\
2.4 \% \\
\end{array}$ & 11 & $144^{*}$ & $\begin{array}{ll}1143 & 1 \\
4 \% & \\
\end{array}$ & 1144 * & $\begin{array}{ll}1143 & 1 \\
4 \% & \\
\end{array}$ & $144^{*}$ \\
\hline $\begin{array}{l}\text { AlCrMnMoTi } \\
\mathrm{Al} \geq 15 \%\end{array}$ & $\begin{array}{ll}2233 & 1 \\
3.7 \% & \\
\end{array}$ & $1143^{*}$ & $\begin{array}{l}2233 \\
3.7 \% \\
\end{array}$ & 11 & $143 *$ & $\begin{array}{ll}2233 & 1 \\
6 \% & \\
\end{array}$ & 1143 * & $\begin{array}{ll}2233 & 1 \\
6 \% & \\
\end{array}$ & $143 *$ \\
\hline $\begin{array}{l}\text { AlCrMnMoTi } \\
\mathrm{Cr} \geq 15 \%\end{array}$ & $\begin{array}{ll}2233 & 1 \\
3.7 \% & \\
\end{array}$ & 1143 * & $\begin{array}{l}2233 \\
3.7 \% \\
\end{array}$ & 11 & $143 *$ & $\begin{array}{ll}2233 & 1 \\
6 \% & \\
\end{array}$ & $1143^{*}$ & $\begin{array}{ll}2233 & 1 \\
6 \% & \\
\end{array}$ & $143 *$ \\
\hline $\begin{array}{l}\text { AlCrMnMoTi } \\
\mathrm{Al}+\mathrm{Cr} \geq 15 \%\end{array}$ & $\begin{array}{ll}2233 & 1 \\
3.7 \% & \end{array}$ & $1143^{*}$ & $\begin{array}{l}2233 \\
3.7 \%\end{array}$ & 11 & $143^{*}$ & $\begin{array}{ll}2233 & 1 \\
6 \% & \end{array}$ & 1143 * & $\begin{array}{l}2233 \\
6 \%\end{array}$ & $143 *$ \\
\hline
\end{tabular}

Table 5. HEA island center(s) compositions, determined with different distance and boundary criteria at $800 \mathrm{~K}$, under the constraint of having four or more elements present in a $\geq 10 \%$ concentration. Below each composition is the distance to the nearest non-HEA composition. The elements concentration spacing is $4 \%$ for the six element alloys and $2 \%$ for the five element alloys. An asterix behind an island center composition indicates there are other island center compositions nearby that have an equally long distance to a nearest non-HEA composition.

\begin{tabular}{|c|c|c|c|c|}
\hline & \multicolumn{4}{|c|}{ Distance and Boundary Criteria } \\
\hline & \multicolumn{2}{|c|}{ Euclidean Distance } & \multicolumn{2}{|c|}{ Manhattan Distance } \\
\hline & Boundary_on & Boundary_off & Boundary_on & Boundary_off \\
\hline Alloy, Constraint & $\%$ Al Cr Mn Nb Ti V & & & \\
\hline $\begin{array}{l}\text { AlCrMnNbTiV } \\
4 \text { elem. } \geq 10 \%\end{array}$ & $\begin{array}{l}171317 \quad 1 \quad 943 * \\
6.3 \%\end{array}$ & $\begin{array}{l}11 \quad 1 \quad 9171349 \\
1711 \quad 17 \quad 1 \quad 945^{*} \\
511 \quad 1132149^{*} \\
5 \quad 111132545^{*} \\
7.5 \%\end{array}$ & $\begin{array}{l}171317 \quad 1 \quad 943 \text { * } \\
12 \%\end{array}$ & $\begin{array}{l}171117 \quad 1 \quad 945 \text { * } \\
16 \%\end{array}$ \\
\hline $\begin{array}{l}\text { AlCrMnNbTiV } \\
5 \text { elem. } \geq 10 \%\end{array}$ & $\begin{array}{l}171317 \quad 11141 \\
6.3 \%\end{array}$ & $\begin{array}{l}131313 \quad 11149 \\
7.5 \%\end{array}$ & $\begin{array}{l}171317 \quad 11141 \\
12 \%\end{array}$ & $\begin{array}{l}111313 \quad 11349 \text { * } \\
13111131349 \text { * } \\
12 \%\end{array}$ \\
\hline $\begin{array}{l}\text { AlCrMnNbTiV } \\
6 \text { elem. } \geq 10 \%\end{array}$ & - & - & - & - \\
\hline $\begin{array}{l}\text { AlCrMoNbTiV } \\
4 \text { elem. } \geq 10 \%\end{array}$ & $\begin{array}{l}1152911341 \text { * } \\
6.3 \%\end{array}$ & 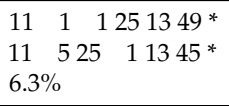 & $\begin{array}{l}11 \quad 12951341 \text { * } \\
12 \%\end{array}$ & 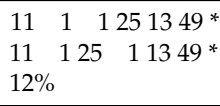 \\
\hline $\begin{array}{l}\text { AlCrMoNbTiV } \\
5 \text { elem. } \geq 10 \%\end{array}$ & $\begin{array}{l}131117 \quad 11345 \\
5.5 \%\end{array}$ & $\begin{array}{l}131117 \quad 11345 \\
5.7 \%\end{array}$ & $\begin{array}{lrr}11 & 117131345^{*} \\
13 & 1319 & 11341^{*} \\
13 & 11 & 13171145^{*} \\
8 \% & \end{array}$ & 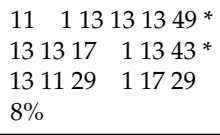 \\
\hline $\begin{array}{l}\text { AlCrMoNbTiV } \\
6 \text { elem. } \geq 10 \%\end{array}$ & - & - & - & - \\
\hline $\begin{array}{l}\text { AlCrFeTiV } \\
4 \text { elem. } \geq 10 \%\end{array}$ & - & - & - & - \\
\hline $\begin{array}{l}\text { AlCrFeTiV } \\
5 \text { elem. } \geq 10 \%\end{array}$ & - & - & - & - \\
\hline $\begin{array}{l}\text { AlCrMnMoTi } \\
4 \text { elem. } \geq 10 \%\end{array}$ & $\begin{array}{l}1617 \quad 11749 \text { * } \\
1.4 \%\end{array}$ & $\begin{array}{l}1617 \quad 11749 \text { * } \\
1.4 \%\end{array}$ & $\begin{array}{l}1617 \quad 11749 \text { * } \\
2 \%\end{array}$ & $\begin{array}{l}1617 \quad 11749 \text { * } \\
2 \%\end{array}$ \\
\hline $\begin{array}{l}\text { AlCrMnMoTi } \\
5 \text { elem. } \geq 10 \%\end{array}$ & - & - & - & - \\
\hline
\end{tabular}


Tables 4 and 5 show that the options for selecting HEAs with minimum $\mathrm{Al}$ and/or $\mathrm{Cr}$ content or four or more elements present in 10\% or higher concentration are limited. Imposing such constraints decreases HEA island sizes, down to 0 when requiring that all elements have a $10 \%$ or higher concentration. AlCrMnNbTiV has the largest islands of HEA compositions that contain a high enough percentage of $\mathrm{Al}$ to promote oxidation resistance.

\subsection{Melting Temperature Ranges}

From a production point of view it is preferable to select alloys with narrow solidification temperature ranges in order to achieve solidification with minimal unmixing, or with unmixing on the smallest possible length scales. Since we only determine data at temperature intervals of $50 \mathrm{~K}$, we can only roughly estimate solidification temperature ranges. Therefore, in Table 6 we list the number of $50 \mathrm{~K}$ spaced temperatures that fall within the solidification ranges.

Table 6. Number of $50 \mathrm{~K}$ spaced data points in the solidification temperature ranges of alloys.

\begin{tabular}{lccccc}
\hline Alloy & $\begin{array}{l}\text { Average, All } \\
\text { Compos. }\end{array}$ & $\begin{array}{l}\text { Average Over HEA } \\
\text { Compos. at 800 K }\end{array}$ & $\begin{array}{l}\text { Average Over Non- } \\
\text { HEA Compos. at 800 K K }\end{array}$ & $\begin{array}{l}\text { Max. of All } \\
\text { Compos. }\end{array}$ & $\begin{array}{l}\text { Max. of HEA } \\
\text { Compos. }\end{array}$ \\
\hline AlCrMnNbTiV & 2.42 & 1.27 & 2.46 & 15 & 4 \\
AlCrMoNbTiV & 3.20 & 3.28 & 3.19 & 15 & 6 \\
AlCrFeTiV & 2.42 & 0.43 & 2.42 & 9 & 2 \\
AlCrMnMoTi & 4.21 & 1.68 & 4.21 & 15 & 4 \\
\hline
\end{tabular}

Table 6 shows that alloy compositions that are a single phase HEAs at $800 \mathrm{~K}$ generally have rather narrow solidification ranges, in all cases six intervals of $50 \mathrm{~K}$ or less. On average the most promising HEA alloys from the AlCrMnNbTiV and AlCrMoNbTiV type have solidification ranges of just 1.27 and $3.2850 \mathrm{~K}$ intervals. So it appears as if selecting compositions that are single phase HEAs at $800 \mathrm{~K}$ simultaneously also selects alloys that have desirable solidification behavior. However, the alloy with by far the narrowest solidification range, AlCrFeTiV, is also the poorest HEA former in our study. As in Section 3.4, the higher temperature results in this section have an extra deviation from experimental observations due to the artificial homogeneity and lack of any concentration gradients in our calculations.

\section{Conclusions}

We used the Thermo-Calc CALPHAD database to computationally investigate the HEA forming qualities between 800 and $2800 \mathrm{~K}$ of four alloys, AlCrMnNbTiV, AlCrMoNbTiV, AlCrFeTiV and AlCrMnMoTi. These alloys contain elements that provide oxidation resistance and were previously predicted to be HEAs at high temperature at equi-atomic compositions. Simple variations of the element concentrations away from being equi-atomic can already greatly extend the temperature range over which the alloys are HEAs. However, with a brute force compositions scanning approach, alloy compositions could be found that remain HEAs down to $800 \mathrm{~K}$. By calculating the stable phases for these alloys on grids in five- or six-dimensional composition spaces, we were able to determine islands of low temperature HEA stability. Making binary alloy projections of these high-dimensional islands gives information about the overall HEA forming qualities of the alloys as well as about the roles of individual elements within the alloys. The HEA forming qualities of a combination of elements can also be gleaned from the percentage of compositions that form HEAs as a function of temperature. The compositions of the centers of the HEA islands remain HEAs under small composition changes and thus have some margin of error against inaccuracies in the TC HEA database. Applying our methodology to four alloys, we find that $\mathrm{AlCrMnNbTiV}$ and $\mathrm{AlCrMoNbTiV}$ are good HEA formers that have HEA islands of non-negligible size at $800 \mathrm{~K}$ and that these islands grow rapidly with increasing temperature. AlCrMnMoTi has very few HEA compositions at $800 \mathrm{~K}$ but rapidly develops them with increasing temperature. AlCrFeTiV is a poor HEA former at any temperature. For all alloys that have HEA islands, the island centre compositions correspond to what are essentially ternary 
alloys. Therefore these most interesting compositions are at best medium entropy alloys rather than high entropy alloys. The elements mostly absent from island centre compositions include $\mathrm{Al}$ and $\mathrm{Cr}$ for $\mathrm{AlCrMnNbTiV}$ and $\mathrm{AlCrMoNbTiV}$. Alloys with these compositions thus lack elements that are important for oxidation resistance. Imposing constraints for minimal amounts of $\mathrm{Al}$ and/or $\mathrm{Cr}$ or four or more alloying elements with $>10 \%$ concentration rapidly diminishes the number of available HEA compositions, though there are compositions that meet both the requirements of forming HEAs at $800 \mathrm{~K}$ and containing substantial amounts of $\mathrm{Al}$ and/or $\mathrm{Cr}$. These requirements can be combined with the additional requirement of having a narrow solidification range. Alloy compositions around $\mathrm{Al}_{25} \mathrm{Cr}_{7} \mathrm{Mn}_{25} \mathrm{Nb}_{1} \mathrm{Ti}_{1} \mathrm{~V}_{41}$ or $\mathrm{Al}_{21} \mathrm{Cr}_{7} \mathrm{Mn}_{21} \mathrm{Nb}_{1} \mathrm{Ti}_{9} \mathrm{~V}_{41}$ offer the best compromise between these three different criteria, according to our CALPHAD predictions. Since CALPHAD predictions are sometimes at odds with experimental results [15], we propose these two compositions for experimental verification.

Supplementary Materials: The following are available online at http:/ /www.mdpi.com/1099-4300/20/12/911/s1. The supplementary material contains the list of compositions calculated and for each composition whether that composition is a HEA at $800 \mathrm{~K}$ or not and what the phases and phase fractions are at $800 \mathrm{~K}$ for the four alloy systems.

Author Contributions: T.P.C.K. carried out the TC calculations, the processing of the TC output and prepared the manuscript. D.S. carried out the analysis to determine HEA island locations and sizes in composition spaces. M.H.F.S. contributed the main idea of determining HEA islands with a CALPHAD database, added further ideas during discussions throughout the research and did several rounds of critical reading and making suggestions during the preparation of the manuscript.

Funding: This research received funding through the ERA-NET Integrated computational materials engineering (ICME) program under project 4316 "HEAMODELL" as financed by NWO "domein Exacte en Natuurwetenschappen".

Acknowledgments: The authors thank Bengt Hallstedt, James Saal and Ake Jansson and others from Thermo-Calc support for their kind help with TC questions. The authors also thank Richard Huizinga for help with the TC license server and Fritz Körmann for general HEA discussions.

Conflicts of Interest: The authors declare no conflict of interest. The founding sponsor had no role in the design of the study; in the collection, analyses, or interpretation of data; in the writing of the manuscript, and in the decision to publish the results.

\section{References}

1. Maa, D.; Grabowski, B.; Körmann, F.; Neugebauer, J.; Raabe, D. Ab initio thermodynamics of the CoCrFeMnNi high entropy alloy: Importance of entropy contributions beyond the configurational one. Acta Mater. 2015, 100, 90-97. [CrossRef]

2. Raabe, D.; Tasan, C.C.; Springer, H.; Bausch, M. From High-Entropy Alloys to High-Entropy Steels. Steel Res. Int. 2015, 86, 1127-1138. [CrossRef]

3. Kivy, M.B.; Kriewall, C.S.; Zaeem, M.A. Formation of chromium-iron carbide by carbon diffusion in AlXCoCrFeNiCu high-entropy alloys. Mater. Res. Lett. 2018, 6, 321-326. [CrossRef]

4. Li, Z.; Raabe, D. Strong and Ductile Non-equiatomic High-Entropy Alloys: Design, Processing, Microstructure, and Mechanical Properties. JOM 2017, 69, 2099-2106. [CrossRef]

5. Gorsse, S.; Miracle, D.B.; Senkov, O.N. Mapping the world of complex concentrated alloys. Acta Mater. 2017, 135, 177-187. [CrossRef]

6. Li, Z.; Körmann, F.; Grabowski, B.; Neugebauer, J.; Raabe, D. Ab initio assisted design of quinary dual-phase high-entropy alloys with transformation-induced plasticity. Acta Mater. 2017, 136, 262-270. [CrossRef]

7. Deng, Y.; Tasan, C.C.; Pradeep, K.G.; Springer, H.; Kostka, A.; Raabe, D. Design of a twinning-induced plasticity high entropy alloy. Acta Mater. 2015, 94, 124-133. [CrossRef]

8. Uzera, B.; Picak, S.; Liu, J.; Jozaghi, T.; Canadinc, D.; Karaman, I.; Chumlyakov, Y.I.; Kireeva, I. On the mechanical response and microstructure evolution of $\mathrm{NiCoCr}$ single crystalline medium entropy alloys. Mater. Res. Lett. 2018, 6, 442-449. [CrossRef]

9. Nene, S.S.; Frank, M.; Liu, K.; Mishra, R.S.; McWilliams, B.A.; Cho, K.C. Extremely high strength and work hardening ability in a metastable high entropy alloy. Sci. Rep. 2018, 8, 9920. [CrossRef] [PubMed] 
10. Huang, H.; Wu, Y.; He, J.; Wang, H.; Liu, X.; An, K.; Wu, W.; Lu, Z. Phase-Transformation Ductilization of Brittle High-Entropy Alloys via Metastability Engineering. Adv. Mater. 2017, 29, 1701678. [CrossRef] [PubMed]

11. Lilensten, L.; Couzinié, J.; Bourgon, J.; Perrière, L.; Dirras, G.; Prima, F.; Guillot, I. Design and tensile properties of a bcc Ti-rich high-entropy alloy with transformation-induced plasticity. Mater. Res. Lett. 2017, 5, 110-116. [CrossRef]

12. Luo, H.; Li, Z.; Raabe, D. Hydrogen enhances strength and ductility of an equiatomic high-entropy alloy. Sci. Rep. 2017, 7, 9892. [CrossRef] [PubMed]

13. Gao, M.C.; Alman, D.E. Searching for Next Single-Phase High-Entropy Alloy Compositions. Entropy 2013, 15, 4504-4519. [CrossRef]

14. Guruvidyathri, K.; Kumar, K.C.H.; Yeh, J.W.; Murty, B.S. Topologically Close-packed Phase Formation in High Entropy Alloys: A Review of Calphad and Experimental Results. JOM 2017, 69, 2113-2124. [CrossRef]

15. Saal, J.E.; Berglund, I.S.; Sebastian, J.T.; Liaw, P.K.; Olson, G.B. Equilibrium high entropy alloy phase stability from experiments and thermodynamic modeling. Scripta Mater. 2018, 146, 5-8. [CrossRef]

16. Otto, F.; Dlouhý, A.; Pradeep, K.G.; Kuběnová, M.; Raabe, D.; Eggeler, G.; George, E.P. Decomposition of the single-phase high-entropy alloy $\mathrm{CrMnFeCoNi}$ after prolonged anneals at intermediate temperatures. Acta Mater. 2016, 112, 40-52. [CrossRef]

17. Mao, H.; Chen, H.; Chen, Q. TCHEA1: A Thermodynamic Database Not Limited for "High Entropy" Alloys. J. Phase Equilib. Diffus. 2017, 38, 353-368. [CrossRef]

18. Chen, H.; Mao, H.; Chen, Q. Database development and Calphad calculations for high entropy alloys: Challenges, strategies, and tips. Mater. Chem. Phys. 2018, 210, 279-290. [CrossRef]

19. Senkov, O.N.; Miller, J.D.; Miracle, D.B.; Woodward, C. Accelerated exploration of multi-principal element alloys for structural applications. CALPHAD 2015, 50, 32-48. [CrossRef]

20. Senkov, O.N.; Miller, J.D.; Miracle, D.B.; Woodward, C. Accelerated exploration of multi-principal element alloys with solid solution phases. Nat. Commun. 2015, 6, 6529. [CrossRef] [PubMed]

21. Menou, E.; Toda-Caraballo, I.; Pineau, C.; Bertrand, E.; Ramstein, G.; Tancret, F. Evolutionary design of strong and stable high entropy alloys using multi-objective optimisation based on physical models, statistics and thermodynamics. Mater. Des. 2018, 143, 185-195. [CrossRef]

22. Abu-Odeh, A.; Galvan, E.; Kirk, T.; Mao, H.; Chen, Q.; Mason, P.; Malak, R.; Arróyave, R. Efficient exploration of the High Entropy Alloy composition-phase space. Acta Mater. 2018, 152, 41-57. [CrossRef]

23. Gheribi, A.E.; Pelton, A.D.; Bélisle, E.; le Digabel, S.; Harvey, J.-P. On the prediction of low-cost high entropy alloys using new thermodynamic multi-objective criteria. Acta Mater. 2018, 161, 73-82. [CrossRef]

24. Tang, Z.; Gao, M.C.; Diao, H.; Yang, T.; Liu, J.; Zuo, T.; Zhang, Y.; Lu, Z.; Cheng, Y.; Zhang, Y.; et al. Aluminum Alloying Effects on Lattice Types, Microstructures, and Mechanical Behavior of High-Entropy Alloys Systems. JOM 2013, 65, 1848-1858. [CrossRef] 